\title{
EL CICLO EGIPCIO DE LA ETERNA REGENERACIÓN A TRAVÉS DE LA TUMBA DE NEBAMUN: SU INFLUENCIA EN LA PINTURA HISTÓRICA DE SIR LAWRENCE ALMA-TADEMA
}

\author{
The Egyptian Cycle of Eternal Regeneration through the Tomb of Nebamun: \\ His Influence on the Historical Painting of Sir Lawrence Alma-Tadema
}

\author{
María Victoria Álvarez Rodríguez \\ mvalvarez@usal.es \\ Universidad de Salamanca. España \\ Fecha de recepción: 28/02/2019 \\ Fecha de aceptación: 15/05/2019
}

RESUMEN: Con la eclosión de Romanticismo en el continente europeo, una creciente pasión por Oriente (desde la Arabia de Las mil y una noches hasta la Granada nazarita, pasando por el Egipto faraónico) se dejó sentir poderosamente en el panorama de las artes y la literatura, perdurando incluso cuando el influjo de dicho movimiento ya había llegado a su fin. A medida que avanzaba la centuria, esa fascinación fue evolucionando desde una recreación histórica más caprichosa y personal hasta un profundo interés por el rigor arqueológico, algo especialmente palpable en los pintores ingleses que, en las últimas décadas de la época victoriana, sucumbieron al encanto de la temática egipcia. Uno de los mejores ejemplos es sin duda el de Sir Lawrence Alma-Tadema (1836-1912), cuya obra se caracterizó por la inclusión de ropajes, tocados, mobiliario y numerosos detalles basados en el estudio minucioso de objetos pertenecientes a la Antigüedad. En nuestro estudio nos proponemos analizar la influencia ejercida por el ciclo pictórico de la tumba de Nebamun en la producción de este artista, comparando sus cuadros ambientados en el Antiguo Egipto con los fragmentos de dicho ciclo conservados en el Museo Británico. De este modo comprobaremos hasta qué punto su pintura es deudora de ellos, tanto en lo concerniente a la temática de algunos de esos cuadros como en cuanto a la inclusión directa de las escenas de Nebamun como un elemento decorativo más de sus interiores.

Palabras clave: Sir Lawrence Alma-Tadema; Nebamun; Pintura victoriana; Pintura egipcia; Arqueología; Iconografía funeraria. 
ABSTRACT: With the emergence of Romanticism on the European continent, a growing passion for the Orient (from Arabian One Thousand and One Nights to Nazarite Granada, passing through Pharaonic Egypt) was strongly felt in the panorama of arts and literature, lasting even when the influence of that movement had already come to an end. As the century progressed, that fascination evolved from a more whimsical and personal historical recreation to a deep interest in archaeological rigor, something especially palpable in English painters who, in the last decades of the Victorian era, succumbed to the charm of the Egyptian theme. One of the best examples is undoubtedly that of Sir Lawrence Alma-Tadema (1836-1912), whose work was characterized by the inclusion of clothing, headdresses, furniture and numerous details based on the meticulous study of objects belonging to antiquity. In our study we propose to analyze the influence exerted by the pictorial cycle of Nebamun's tomb in the production of this artist, comparing his paintings set in Ancient Egypt with the fragments of that cycle preserved in the British Museum. In this way we will check to what extent his painting is indebted to them, both in regard to the subject matter of some of these paintings and in terms of the direct inclusion of the Nebamun scenes as a decorative element of their interiors.

Keywords: Sir Lawrence Alma-Tadema; Nebamun; Victorian painting; Egyptian painting; Archeology; Funerary iconography.

SUMARIO: 1. Introducción. 2. Sir Lawrence Alma-Tadema (1836-1912). 3. Las pinturas de la tumba de Nebamun. 4. La influencia de Nebamun en las obras de Alma-Tadema. 5. Conclusiones. 6. Referencias bibliográficas.

\section{INTRODUCCIÓN}

Durante el transcurso de la centuria decimonónica, desde la Revolución Francesa hasta los albores de la Primera Guerra Mundial, el continente europeo experimentó un curioso fenómeno conocido posteriormente como "egiptomanía», similar al que se había dejado sentir entre pueblos mucho más cercanos en el tiempo al Antiguo Egipto como los fenicios, los griegos o los romanos. La principal diferencia fue que, en este caso, la pasión por la civilización egipcia poseyó un componente crítico, científico y positivista mucho mayor, debido principalmente a la cantidad de descubrimientos que empezaron a llevarse a cabo por aquel entonces. Podemos decir que la Campaña Egipcia (1798-1801) de Napoleón Bonaparte (1769-1821) actuó como principal catalizador de todo esto, así como punto de partida para otros hitos tan relevantes como la publicación de las obras de Dominique Vivant Denon (1747-1825) al respecto, el hallazgo de la Piedra Rosetta por los franceses en 1799, pasando más tarde a manos inglesas, o la decodificación de la escritura jeroglífica que Jean-François Champollion (1790-1832) logró realizar gracias a ella. Paralelamente, la cantidad de obras de arte con las que tanto los ingleses como los franceses nutrieron sus principales museos contribuyó a aproximar esta civilización al gran público, hasta el punto de que la influencia del Antiguo Egipto acabó dejándose sentir en la moda, el mobiliario, el diseño de interiores y, por supuesto, también el arte. Esto alcanzó su punto álgido, ya a comienzos del siglo XX, con el hallazgo de la tumba de Tutankhamón (en torno a 1341-1323 a. de C.) llevado a cabo por 
Howard Carter (1874-1939) en 1922 (Conner 1983, Humbert y Price 2012, Moser 2015 y Fritze 2016).

Conviene destacar, por otra parte, lo imbuida que se encontraba esta pasión por el Antiguo Egipto de la mentalidad colonialista decimonónica, que buscaba establecer una suerte de reivindicación de esta cultura por parte de sus «herederos» europeos. Como señala Said en sus estudios a este respecto, esa hegemonía puramente occidental llevó no solo a estudiosos como los arqueólogos, los historiadores y los historiadores del arte, sino también a los escritores y artistas de la misma época, a establecer una especie de diálogo unidireccional con el que se pretendía justificar la dominación de Egipto por parte de potencias como la francesa o la inglesa (1994, 2003). Esta reivindicación cultural, a la postre, no hacía sino aumentar la percepción racista de la población autóctona, algo muy apreciable en la pintura decimonónica de temática egipcia; sirva como ejemplo el contraste entre el tipo más occidentalizado (caucásico durante los siglos anteriores, más mediterráneo a partir del XIX) de personajes tan paradigmáticos como Cleopatra (69-30 a. de C.) y el de raíces africanas de las sirvientas que suelen aparecer con ella. En dichas representaciones se unen dos conceptos que arraigaron con fuerza en el Romanticismo: la sexualización de la mujer oriental y la capacidad de seducción de una femme fatale con encarnaciones tan diversas como Salomé, Lilith, Dalila o Mesalina (Chang 2017, 188).

Esta imagen tan idealizada de las egipcias, irreal por surgir de la imaginación del hombre occidental más que de un estudio objetivo de la realidad, ejerció un poderosísimo influjo sobre los pintores que en la Inglaterra de la reina Victoria (18191901) abordaron la cuestión egipcia en sus obras. Sirvan como ejemplo las bellezas que pueblan muchos de los cuadros de Sir Edward Poynter (1836-1919), cuya sensualidad se entremezcla a menudo con un incitante paganismo, o las muchachas de ojos y cabello oscuro y dulzura lánguida de Edwin Longsden Long (1829-1891) (Meulenaere 1992). En el caso de Sir Lawrence Alma-Tadema (1836-1912), el artista alrededor del cual gira nuestro estudio, la plasmación de este erotismo oriental no poseyó tanta importancia como la minuciosa recreación que supo llevar a cabo de la vida cotidiana en el Antiguo Egipto, característica que le hizo destacar por encima de los pintores mencionados ya en su propia época.

\section{SIR LAWRENCE ALMA-TADEMA (1836-1912)}

De origen neerlandés pero afincado en Inglaterra desde 1870, Alma-Tadema pasó a la historia como uno de los artistas que mejor supieron encarnar la unión, a finales de la época victoriana, del neoclasicismo heredero de la pintura académica y el esteticismo más característico del ambiente finisecular. Nacido en Dronryp en 1836 y formado en Amberes desde 1852, primero en el estudio de Egide Charles Gustave Wappers (1803-1874) y más tarde en el de Jan August Hendrik Leys (1815- 
1869), demostró desde un primer momento un interés por los temas históricos que le acompañaría durante el resto de su vida, si bien fue variando el foco de su atención pasando de una época a otra. Fue Leys precisamente quien inculcó en Alma-Tadema la minuciosidad con la que siempre realizó la documentación para sus obras, apreciable en las primeras con las que cosechó un notable éxito en las exposiciones de Amberes y Ámsterdam; por entonces, los temas basados en la historia de los merovingios, como The Education of the Children of Clovis (1861) o Fredegund by the Deathbed of Bishop Praetextatus (1864), se contaban entre los favoritos del pintor, aunque no tardaría en decantarse por los inspirados en Egipto y Roma por parecerle mucho más adecuados para atraer al gran público (Barrow, 2003, p. 6).

Esas ambientaciones en la Antigüedad se convirtieron, efectivamente, en una de sus principales señas de identidad, sobre todo tras su traslado definitivo a Londres en el contexto de la guerra franco-prusiana de los años 70 . Allí cambió su nombre del Lourens neerlandés al británico Lawrence, además de emprender un proceso de identificación de sus obras añadiendo un "opus $X$ » a su firma para dificultar cualquier eventual intento de falsificación (Barrow, 2003, p. 62). A esta etapa pertenecen sus cuadros más conocidos y ambiciosos ambientados en la Roma imperial, como An Audience at Agrippa's (1876), The Roses of Heliogabalus (1888) o Unconscious Rivals (1893); además de basarse en fuentes históricas sobre la época para pintarlos, Alma-Tadema se apoyó en los estudios y dibujos que realizó durante sus viajes a Roma y Pompeya, así como en las fotografías adquiridas en los mismos. Cabe mencionar, además, que su predilección por esta clase de pintura no le impidió cultivar otras expresiones artísticas, como el paisaje, el retrato y la acuarela y, durante los últimos años de su vida, también el diseño de vestuario para producciones teatrales y mobiliario inspirado en la Antigüedad (Richards, 2009, p. 164).

Perfeccionista hasta el exceso, es fácil comprender por qué su estilo sedujo de tal modo a la sociedad victoriana de aquel entonces, en un momento en que el esteticismo y el afán por retratar la belleza en estado puro encontraron la plasmación de estos anhelos en el lánguido abandono de sus escenas. El hedonismo practicado por sus personajes, cuyos tipos caucásicos le hicieron ganarse la reputación de retratar a "victorianos en toga», consiguió conectar con la sensibilidad de finales del siglo XIX permitiendo una actualización constante de sus temas. Esa identificación con el modus vivendi de épocas pasadas también se encuentra muy presente, como analizaremos a continuación, en los lienzos inspirados en el Egipto faraónico que realizó al comienzo de su carrera, pese a constituir un porcentaje realmente exiguo comparado con el de sus pinturas romanas.

De los cuatrocientos ocho cuadros a los que asciende el total de la producción de Alma-Tadema, solo veintiséis pueden incluirse en esta categoría, pertenecientes, en su mayor parte, a las décadas de 1860 y 1870 (DeMaria Smith, 2011, p. 150). Sorprende este detalle si tenemos en cuenta que las más emblemáticas de esas pinturas, como Pastimes in Ancient Egypt 3.000 Years Ago (1863), Egyptian 
Chess Players (1865), The Death of the Pharaoh's Firstborn Son (1872), The Egyptian Widow in the Time of Diocletian (1872) o Joseph, Overseer of Pharaoh's Granaries (1874), fueron realizadas mucho antes de que nuestro artista tuviera la oportunidad de conocer Egipto de primera mano.

Su primer viaje a este país, en efecto, no tuvo lugar hasta la tardía fecha de 1902, coincidiendo con el acto de inauguración de la Presa Baja de Asuán; fue precisamente Sir John Aird (1833-1911), propietario de la compañía que se ocupó de dicho proyecto, quien le encargó personalmente el cuadro The Finding of Moses (1904) y le invitó a viajar a Egipto con personalidades tan importantes como Winston Churchill (1874-1965) para que pudiera inspirarse in situ (Huckvale, 2012, p. 124). Ello quiere decir que su conocimiento había sido indirecto hasta entonces, aunque la profesionalidad con la que se apoyó en los numerosos recursos que se han identificado a día de hoy contribuyó a que sus obras poseyeran ese rigor arqueológico tan alabado durante toda su trayectoria.

Entre las fuentes escritas manejadas por Alma-Tadema se encontraban, como no podía ser de otro modo, títulos tan consagrados como Voyage dans la Basse et la Haute Egypte pendant les campagnes du General Bonaparte (1802) y Description de l'Égypte (1809-1813) del ya mentado Dominique Vivant Denon, responsables en gran medida de sembrar la semilla de la egiptomanía en el contexto del París napoleónico. También la publicación de la novela Eine ägyptische Königstochter (1864) del egiptólogo alemán Georg Moritz Ebers (1837-1898), más cercana en el tiempo a Alma-Tadema y poseedora de la misma fascinación romantizada por la época, pudo contribuir a avivar su temprano interés por Egipto (Gaunt, 1953, p. 76 y Huckvale, 2012, p. 120). Fue, no obstante, la célebre obra de Sir John Gardner Wilkinson (1797-1875) titulada The Manners and Customs of the Ancient Egyptians (1837) la que ejerció una influencia más decisiva en su recreación histórica, al igual que ocurrió con la mayoría de pintores victorianos que se decantaron por dicha ambientación (Thompson, 2010, p. 155). Se ha localizado de hecho un elevado número de dibujos copiados por Alma-Tadema a partir de los grabados incluidos en la obra de Wilkinson, acompañados de anotaciones en neerlandés y francés que delatan su realización en una etapa temprana de su trayectoria (Verhoogt, 2018, p. 3 y Becker, Morris y Treuherz, 1996, p. 169). De Wilkinson extrajo Alma-Tadema la inmensa mayoría de los objetos de uso cotidiano que, incluidos en escenas deliberadamente intrascendentes, le hicieron merecedor de encendidos elogios por su rigor arqueológico, mientras que las ilustraciones pertenecientes a The Grammar of Ornament (1856) del arquitecto Owen Jones (1809-1874) bien pudieron influirle en los detalles decorativos de sus interiores.Por otra parte, la fotografía que tan en boga se encontraba por aquel entonces le resultó también de una enorme utilidad. Alma-Tadema dejó a su muerte una colección de 1.200 fotografías, iniciada presumiblemente a comienzos de la década de 1860, a la vez que se adentraba en la pintura ambientada en el Antiguo Egipto; estas imágenes se organizaban en 
150 volúmenes descritos por él mismo como de "greatest use» y pasan por ser el mayor archivo de esas características perteneciente a un pintor, depositado hoy en la biblioteca de la Universidad de Birmingham (Vaizey, 1982, p. 20 y Esposito, 2003, p. 88). Entre dichas fotografías podemos encontrar copias de las expuestas en 1862 en la International Exhibition de South Kensington por Francis Frith (1822-1898) y Francis Bedford (1815-1894), realizadas durante sus expediciones a Oriente prestando especial atención a monumentos egipcios de El Cairo, Tebas y Filé (Pohlmann, 1996, p. 112). Más adelante, Alma-Tadema adquiriría fotografías de Maxime Du Camp (1822-1894) de temática similar, así como otras tomadas por Philip Henry Delamotte (1821-1889) del Patio Egipcio diseñado para el célebre Crystal Palace; había sido reconstruido en 1854 en Sydenham y contaba con partes nuevas como el mentado patio, un añadido inspirado en monumentos egipcios y diseñado por los también citados Wilkinson y Jones, además del egiptólogo Joseph Bonomi (17961878) (Verhoogt, 2018, pp. 4 y Esposito 2003, 86).

Finalmente, otra de las principales fuentes de inspiración fue la propia colección de arte egipcio del Museo Británico, estudiada personalmente por el artista en 1862 con motivo de su viaje a Londres y de manera continuada a partir de 1870, una vez se hubo instalado en la ciudad (Moser, 2006). Inaugurada por Hans Sloane (1660-1753), fundador de la institución, y ampliada considerablemente gracias a la labor del cónsul Henry Salt (1780-1827) y las adquisiciones realizadas por el ejército inglés tras la Batalla del Nilo de 1798, contaba con ciertas piezas de mobiliario egipcio que, debido precisamente a su cotidianidad, le resultaron a nuestro artista de una enorme utilidad en sus recreaciones. Sirvan como ejemplos un taburete de ébano con incrustaciones de marfil procedente de Tebas, otros dos más sencillos de madera y dos soportes para recipientes, también de madera con una característica decoración mediante travesaños colocados en diagonal, que aparecen de manera recurrente en un porcentaje abrumador de cuadros, no solo de Alma-Tadema sino también de otros artistas contemporáneos como Poynter o Long (Moser 2018). Al aparecer también en los grabados de The Manners and Customs of the Ancient Egyptians, es probable que estos artistas conocieran dichas piezas a través de la obra de Wilkinson si bien, en el caso de Alma-Tadema, contamos con dibujos realizados por él mismo que indican un estudio directo empleando distintas perspectivas (Esposito, 2003, pp. 88-89). Cabe mencionar además que su fascinación por este mobiliario le llevó a adquirir, con el paso del tiempo, algunos objetos de fabricación moderna inspirados en equivalentes del Antiguo Egipto, diseñados por la empresa Liberty \& Co. en las décadas de 1880 y 1890, así como piezas más caprichosas como un diván con dos de sus patas talladas en estilo pompeyano y las otras dos en egipcio (Esposito, 2003, p. 89 y Ash, 1999, p. 3).

Pese a que la intrascendencia de esta clase de objetos los convirtiera en el recurso perfecto para un artista obsesionado con la plasmación de la cotidianidad, en el Museo Británico también había obras capitales de la Historia del Arte egipcio que 
ejercieron una influencia decisiva en su producción. El ciclo pictórico de la tumba de Nebamun es, en este sentido, uno de los ejemplos más elocuentes, puesto que su huella se dejó sentir no solo como un elemento meramente ornamental añadido en los cuadros (incluido como decoración mural, por ejemplo, al fondo de los mismos) sino también como una fuente iconográfica en la que el pintor se inspiró a la hora de plasmar sus escenas y personajes.

\section{LAS PINTURAS DE LA TUMBA DE NEBAMUN}

Consideradas unas de las mejores muestras del arte pictórico del Antiguo Egipto, sorprende que no fueran creadas para ninguna de las sepulturas de la necrópolis real de Deir el-Bahari sino para un enterramiento más sencillo de la orilla oeste. Este pertenecía a un funcionario medio del templo de Ipet Sut, el complejo conocido actualmente con el nombre de Karnak: un escriba y contador de grano llamado Nebamun que debió de vivir entre 1400 y 1350 a. de C., coincidiendo con el reinado de Tutmosis IV (desde 1400 hasta 1390 a. de C.) o de Amenofis III (desde 1390 hasta 1353 a. de C.). Parece ser que Nebamun tenía un especial interés por decorar espléndidamente la parte superior de su tumba, en la que se hallaba la capilla destinada a las ceremonias funerarias de la familia.

Llama la atención de una manera poderosa, si comparamos estas pinturas con las encontradas en tumbas del Valle de los Reyes o el Valle de las Reinas, la exuberancia con la que aparecen representadas las escenas de la vida cotidiana en el Antiguo Egipto. La alegría de vivir tan propia de esta cultura, en consonancia con sus creencias en el ciclo de la perpetua regeneración y la promesa de eternidad en el Más Allá, se refleja a la perfección en cada una de las escenas que se nos han conservado. De este modo, nos encontramos con algunos de los temas funerarios más recurrentes en la pintura como la presentación de ofrendas destinadas al difunto, pero también con escenas de Nebamun, su esposa Hatshepsut y su hija disfrutando de los placeres de la vida eterna, banquetes celebrados en su honor en el Más Allá y representaciones de las actividades que tenían lugar en el templo bajo la supervisión del protagonista. Como podemos apreciar, la vida y la muerte se convierten aquí en las dos caras de la misma moneda, siendo plasmadas en todos los casos con una sofisticación en cuanto a la técnica que ha llevado a algunos estudiosos a aventurar la posibilidad de que realmente fueran realizadas por artistas contratados para trabajar en la necrópolis real, cuyos servicios podría haber requerido Nebamun para su sepultura de manera más o menos subrepticia (Parkinson, 2008, p. 46).

A diferencia de otras pinturas encontradas en esos enterramientos reales, las que nos ocupan sufrieron una notable descontextualización consecuencia de su hallazgo. La tumba fue descubierta en 1820 por Giovanni d'Athanasi (1798-1854), agente griego al servicio del mencionado Henry Salt encargado de excavar en la 
necrópolis tebana entre 1817 y 1827 ; al fallecer sin haber querido revelar a nadie su ubicación exacta, hoy en día desconocemos dónde se encuentra la tumba y si existían en su interior otras pinturas que Athanasi no pudo o quiso arrancar. Esta operación se llevó a cabo de una manera muy poco delicada, sirviéndose de cuchillos, sierras e incluso palancas para desprender las superficies de los muros en los que habían sido pintadas las escenas más llamativas, de ahí que todos esos fragmentos posean unos bordes irregulares (Parkinson, 2008, p. 14).

La descontextualización de la que hablamos no se produjo solamente por haber arrancado esas pinturas de su emplazamiento original, sino también por el reparto de las mismas que se produjo entre museos europeos tan diversos como el Egipcio de Berlín, el de Bellas Artes de Lyon, el Calvet de Aviñón y el Británico de Londres. En cuanto a los once fragmentos con los que cuenta este último, sin duda los más impresionantes, fueron adquiridos por la suma de 2.000 libras, una cantidad tan miserable, en opinión de Salt, que ni siquiera permitió cubrir los gastos de la expedición tebana (Manley y Rée, 2002, p. 203). A este conjunto pertenecen escenas tan emblemáticas como Caza entre papiros, en la que Nebamun aparece cazando garzas en la ribera del Nilo acompañado por su hija y su esposa en una escena con fuertes connotaciones eróticas y de regeneración; Jardín de Nebamun, con una recreación paradisíaca de los Campos de lalú o el Más Allá de los antiguos egipcios; tres fragmentos del Banquete de Nebamun con las famosas bailarinas y músicas, entre las cuales se observan algunos de los escasísimos rostros representados de manera frontal en la pintura egipcia; y otros tres fragmentos relativos a la profesión del difunto donde, además de aparecer sentado con gran dignidad, se retrató a Los gansos de Nebamun y El ganado de Nebamun (Hooper, 2007 y Middleton y Uprichard, 2008).

Evidentemente, desde su instalación en 1835 en el conocido por entonces como Salón Egipcio del Museo Británico, estas pinturas atrajeron la atención de los eruditos deseosos de profundizar en el estudio del arte egipcio, pero también de unos pintores tan fascinados por todas estas «instantáneas» de la vida de Nebamun como por las piezas de mobiliario de las que ya hemos hablado (Parkinson, 2008, p. 18). El caso de Alma-Tadema es uno de los más elocuentes, aunque no el único; muchos de los artistas coetáneos que representaron escenas ambientadas en el Antiguo Egipto incorporaron referencias a este mismo ciclo en sus lienzos. Algunas resultan muy evidentes, como la copia de la escena de los gansos en el fondo de la composición de Obsequies of an Egyptian Cat (1866) de John Reinhard Weguelin (1849-1927), aunque con cambios producidos al fusionarla con otra de las pinturas de Nebamun conocida como Los portadores de ofrendas; o la misma escena incorporada como decoración mural en el ambicioso cuadro An Egyptian Feast (1877) del ya citado Edwin Longsden Long (McCouat, 2015), unida en este caso a otros fragmentos como El ganado de Nebamun y El banquete de Nebamun de la misma tumba y escenas de otras como Nakht y su familia pescando y cazando aves de la 
tumba de Nakht (entre 1400 y 1350 a. de C.). En otras ocasiones, las referencias a Nebamun son más sutiles, como ocurre con la pintura mural sumida en las sombras en Sacred to Pasht (1888), la que se intuye al fondo de A Votary of Isis (1891) o algunos relieves de la columna en la que se apoya una muchacha en The Eastern Favorite (1880). Ninguna de estas plasmaciones, definitivamente, es tan explícita como la realizada por Alma-Tadema en sus obras, ni tampoco tan rigurosa en sus detalles pese a las licencias que el artista, como procederemos a analizar, optó por tomarse en términos de composición.

\section{LA INFLUENCIA DE NEBAMUN EN LAS OBRAS DE ALMA-TADEMA}

Tal como explicamos en su momento, la gran mayoría de los veintiséis cuadros de temática egipcia realizados por el artista se adscriben a las décadas de 1860 y 1870 , de modo que coinciden con los inicios de su carrera. Aunque no se trate del primero, hemos decidido comenzar nuestro análisis con Joseph, Overseer of Pharaoh's Granaries (1874) por ser la pintura en la que la deuda con Nebamun es más evidente, además de poner de manifiesto que la inspiración en su ciclo pictórico fue algo más que tomar una de las escenas halladas en su sepultura para incluirla en el fondo de esta composición [fig. 1].

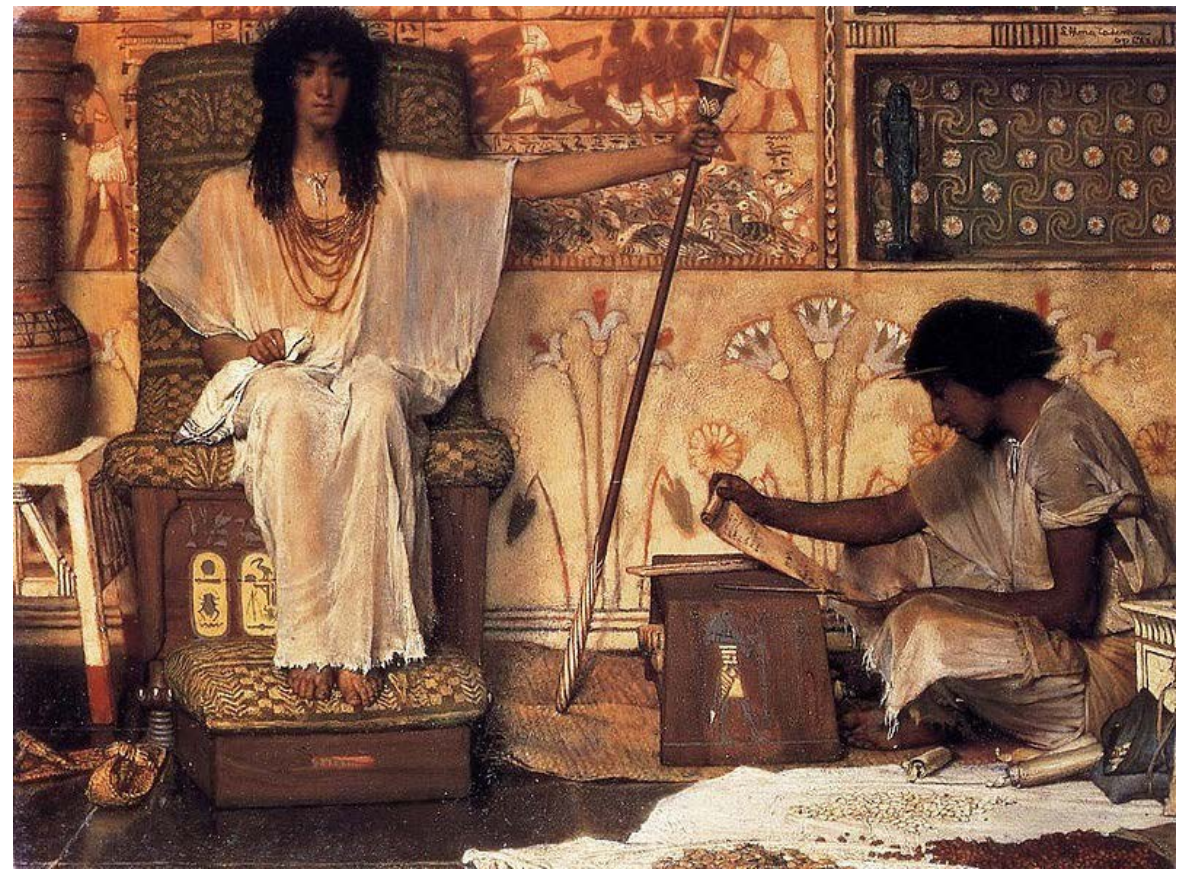

Fig. 1. Joseph, Overseer of Pharaoh's Granaries (1874). Sir Lawrence AlmaTadema. Dahesh Museum of Art. Nueva York. Dominio público. 
Al igual que ocurría con otros temas como la Huida a Egipto o las Doce Plagas, la elección de un episodio bíblico resultaba muy acertada en el contexto de la Inglaterra victoriana, puesto que permitía realzar la dignidad de los personajes cristianos mediante el contraste con unos egipcios retratados como paganos, adoradores de falsos dioses y, precisamente por ello, poseedores de un atractivo casi pecaminoso. En este caso, en el Libro del Génesis (Gen. 37) del Antiguo Testamento se narra cómo José, vendido como esclavo por sus propios hermanos, atrae la atención del faraón mediante su habilidad para interpretar los sueños y, gracias a este peculiar don, consigue advertir a los egipcios de un inminente período de siete años de carestía para el cual pudieron reunir suficientes provisiones. De ese modo, José fue ascendido por el faraón a un puesto importante en su administración, superintendente de los graneros reales; un ejemplo de medra profesional que no es de extrañar que agradara a la burguesía decimonónica, convertida en la clase social más deseosa de demostrar lo mucho que merecía todo cuanto estaba obteniendo.

La plasmación del protagonista, efectivamente, no puede ser más orgullosa: José aparece presidiendo la composición desde un asiento muy ornamentado, en una postura impregnada de dignidad y autoridad y con los ropajes de lino blanco y los collares de oro que, según el texto bíblico, le fueron entregados por el faraón en persona. A sus pies se encuentra un escriba destinado a realzar aún más su superioridad, encargándose de revisar la contabilidad del granero sirviéndose de un pequeño pupitre auxiliar (Barrow, 2003, p. 66). Tanto esta pieza de mobiliario como el asiento de José, las sandalias dejadas a la izquierda de este, el soporte de madera colocado al lado, la peluca del protagonista e incluso el cartucho con el nombre de Tutmosis II (fecha desconocida-1479 a. de C.) que aparece en la parte frontal del asiento fueron recreados por Alma-Tadema a partir de lo descrito en The Manners and Customs of the Ancient Egyptians pero, como ya hemos explicado anteriormente, también mediante el estudio minucioso de algunos objetos del Museo Británico que tuvo la oportunidad de observar en persona (Verhoogt, 2018, p. 10).

Con sus pinturas egipcias ocurrió lo mismo, puesto que el artista escogió la escena de Los gansos de Nebamun para adornar el muro situado detrás de los personajes. La elección no fue meramente estética, sino también iconográfica: al tratarse Nebamun de un funcionario del templo de Amón en Ipet Sut, los paralelismos con el personaje de José saltaban a la vista, y las actividades relacionadas con su profesión que adornaban la sepultura dejaban constancia de en qué consistía esta exactamente. De ahí que podamos observar una escena divida en dos registros horizontales, con el inferior ocupado por entero por la manada de gansos y el superior por seis trabajadores con faldellines y cabezas afeitadas que, siguiendo la orden escrita en jeroglíficos debajo de otro personaje con un bastón («iSentaos y guardad silencio!»), se inclinan ante Nebamun, tres sentados y otros tres besando el suelo; mientras que a la izquierda de la escena, un escriba con sus utensilios sujetos debajo del brazo comprueba las anotaciones realizadas sobre un papiro, acentuando ese paralelismo con el escriba 
que acompaña a José (Parkinson, 2008, p. 97 y McCouat, 2015). Lo más curioso en términos de composición es que, para evitar que la figura del escriba quedara oculta por el respaldo del asiento de José, el pintor no dudó en colocarla a una distancia mayor, con respecto a los gansos, que la que posee en el original, una prueba de que a Alma-Tadema le parecía tan poco importante este detalle como el hecho de que las pinturas de Nebamun no fuesen creadas para un espacio público o la diferencia cronológica de casi un siglo con la época de José (Prettejohn, 1997, p. 33).

Esa estrategia consistente en establecer paralelismos entre la escena representada y la incluida en la decoración de los interiores aparece también en Pastimes in Ancient Egypt 3.000 Years Ago (1863) [fig. 2]. Alma-Tadema renombró varias veces este cuadro (en un principio se había llamado How People Enjoyed Themselves 3.000 Years Ago, más tarde The 18th Dinasty hasta, finalmente, decantarse por el título ya mencionado), merecedor de encendidos elogios desde el momento en que lo pintó. Después de que lo expusiera en Bruselas en 1863, obtuvo una medalla de oro con él en el Salón de París de 1864 y una de segunda clase en la Exposition Universelle también parisina de 1867, para la cual tuvo que ser restaurado después de sufrir desperfectos a causa de una explosión de gas el año anterior (Swanson, 1990, p. 56). Fue, además, un punto de inflexión en el interés de Alma-Tadema por representar temas egipcios, puesto que le sirvió para atraer la atención del marchante de arte Ernest Gambart (1814-1902), quien le encargó, en los siguientes años, otros cuadros de temática similar como Egyptian Chess Players o An Egyptian at His Doorway in Memphis, ambos realizados en 1865 (Verhoogt, 2018, pp. 6-7).

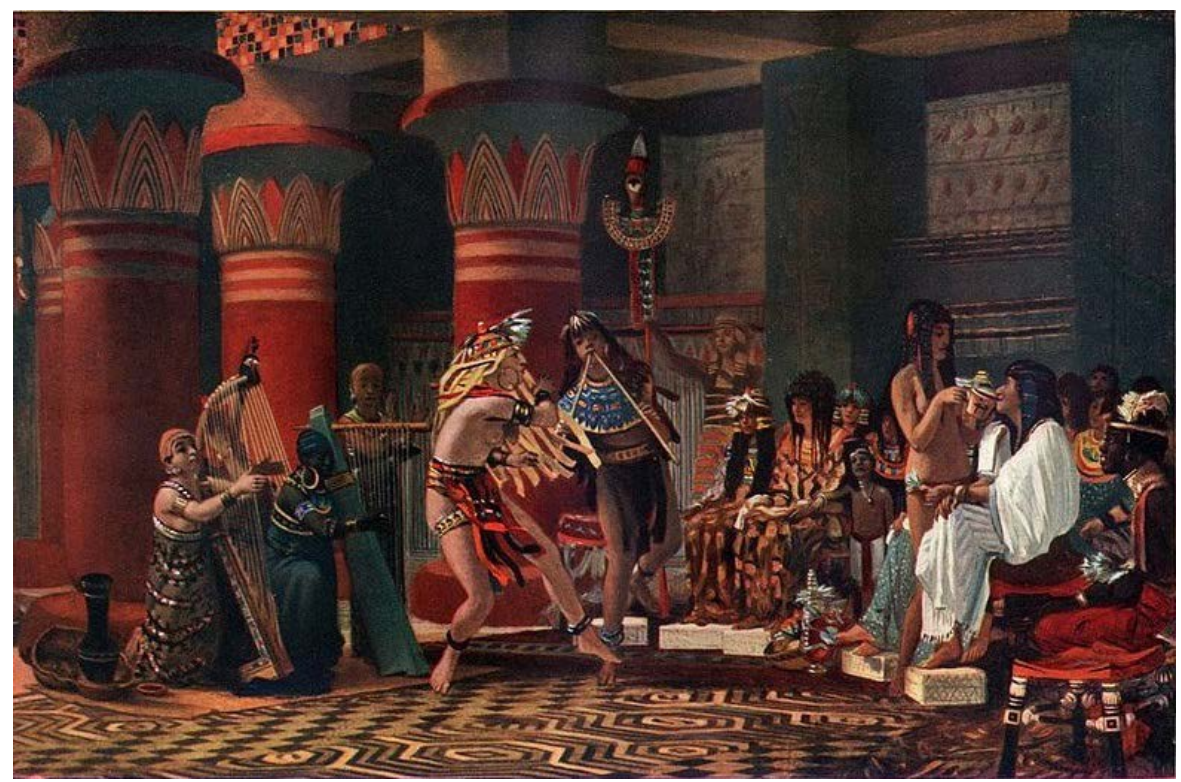

Fig. 2. Pastimes in Ancient Egypt 3.000 Years Ago (1863). Sir Lawrence AlmaTadema. Harris Museum \& Art Gallery. Preston. Dominio Público. 
Regresando a Pastimes in Ancient Egypt 3.000 Years Ago, la escena representada también resulta profundamente egipcia: un banquete ofrecido por un sacerdote llamado Ptahmes a un embajador nubio, amenizado por un grupo de músicos y bailarinas que preside la composición mientras una copera ofrece de beber a los invitados y un sirviente sostiene un estandarte (Barrow, 2003, p. 25). Este tipo de representaciones son recurrentes en la pintura funeraria egipcia, impregnadas de su característica alegría de vivir que, en este contexto, vuelve a adquirir un matiz trascendente: no se perseguía plasmar una escena concreta acontecida en el mundo terrenal sino un ideal de felicidad perpetua en el Más Allá. De nuevo la eterna dualidad egipcia según la cual la presencia de la muerte hacía aún más seductora la vida, de ahí que Alma-Tadema incluyera, en el extremo de la derecha del lienzo, un sarcófago con una momia colocado de pie, siguiendo lo recogido por Heródoto (485-425 a. de C.) y Plutarco (46-127) acerca de las costumbres egipcias en lo tocante a los festejos (Taylor, 2016, p. 222). Curiosamente, esa momia no se aprecia hoy en día en el cuadro de Alma-Tadema, aunque sí en una copia de menor tamaño que se expone en la Auckland Art Gallery de Nueva Zelanda y en grabados como los que vieron la luz en la Gazette des Beaux Arts en 1864 y The Art Journal en 1867 y 1874 (Verhoogt, 2007, p. 462). La explicación puede estar en esa restauración realizada por el propio Alma-Tadema después de que el cuadro sufriera desperfectos: si la parte afectada fue el lateral derecho, donde se encontraba ese sarcófago, pudo haber repintado encima en 1866 dejando esa pared totalmente desnuda, y la inclusión de la momia en grabados posteriores quizás se deba solo a que estaban copiando el de la Gazette des Beaux Arts.

Una vez más, la influencia tanto de la obra de Wilkinson como de objetos egipcios auténticos salta a la vista, aunque no se limitara únicamente a los del Museo Británico. El taburete de ébano con incrustaciones de marfil vuelve a aparecer a la derecha, pero también observamos un arpa del Museo del Louvre e inscripciones del Rijksmuseum de Leiden, estudiados personalmente por el artista con toda probabilidad (Raven, 1980, pp. 105-106). Lo mismo ocurrió con las pinturas de Nebamun, de las cuales Alma-Tadema realizó acuarelas durante sus visitas a Londres que más tarde le sirvieron no solo para incluirlas en las escenas, como acabamos de analizar en el caso del cuadro anterior, sino también como una fuente iconográfica repleta de detalles históricos (Barrow, 2003, p. 25).

Si Los gansos de Nebamun había sido la escena escogida para Joseph, Overseer of Pharaoh's Granaries, los tres fragmentos del Banquete de Nebamun marcaron la pauta a seguir en esta otra representación. Todos los elementos presentes en ellos aparecen también aquí: los invitados cómodamente sentados, el grupo de músicos encargados de entretenerles y las bailarinas danzando a su son. Existen, no obstante, ciertas diferencias como el hecho de que los músicos sean hombres en vez de mujeres en el lienzo de Alma-Tadema y que aparezcan tocando arpas en vez de las palmas y la flauta doble; este instrumento en concreto fue trasladado a una de las 
bailarinas, que también se muestran ligeramente más vestidas que en la pintura de Nebamun. Otros elementos, en cambio, se incorporaron prácticamente sin cambio alguno, como la copera situada a la derecha con un recipiente en las manos con el que da de beber al anfitrión. Tanto la postura como la peluca y el delgadísimo taparrabos son idénticos a los que lleva la copera situada en el registro superior de ese mismo fragmento del Banquete, una figura repetida sin apenas modificaciones hasta cuatro veces más en otro de los fragmentos del Museo Británico.

Esa parte de la pintura mostraba también a los invitados de Nebamun sentados en sillas uno al lado del otro, una disposición que, en cierto modo, vuelve a estar presente en la decoración mural de la estancia recreada por Alma-Tadema. La pared situada al fondo cuenta con una pintura en su parte superior en la que observamos, efectivamente, a una fila de personajes sentados en actitud similar, aunque la influencia no se limita a la tumba que nos ocupa: esta representación se encuentra claramente inspirada por la Lista Real esculpida en Karnak durante el reinado de Tutmosis III (1481-1425 a. de C.) con la enumeración y el retrato de los sesenta y un faraones que le habían precedido (Barrow, 2003, p. 25). Dichos relieves no se encuentran actualmente in situ, sino que en 1843 fueron desmontados por el arqueólogo Émile Prisse d’Avennes (1807-1879) y trasladados de contrabando a París, donde se instalaron en la conocida como Chapelle des ancêtres del Louvre (Volait, 2013, p. 8). Es probable que Alma-Tadema, además de poder contemplarlo en persona durante sus estancias parisinas, se inspirara en el grabado incluido en la obra de Wilkinson, aunque su riqueza de detalles hace más plausible que la referencia a la que prestara más atención fuera otro grabado realizado por Karl Richard Lepsius (1810-1844) para acompañar a su Chronologie der Aegypter (1849) (Wallis Budge, 2010, p. 13).

Cabe mencionar que algunas de estas disposiciones de personajes serán repetidas por Alma-Tadema en posteriores cuadros, con ligeros cambios en la indumentaria y el tipo concreto de objetos que aparecen manejando. Es lo que ocurrirá con The Egyptian Widow in the Time of Diocletian (1872), en la que un grupo de músicos acompaña a una plañidera postrada ante el ataúd de su esposo; todos llevan la cabeza afeitada y vestiduras blancas, y en su caso aparecen tocando un arpa y un sistro claramente inspirados en los grabados de la obra de Wilkinson (Verhoogt, 2018, p. 7). Estos músicos son prácticamente idénticos a los que encontramos tocando palmas y una flauta en The Mummy in the Roman Period (1867), citada en algunas fuentes de la época del artista como Egyptians Lamenting the Dead; el ejercicio de paralelismo realizado entre la propia escena y la decoración que la acompaña vuelve a estar presente en el muro, cuyos relieves muestran a músicos extraídos nuevamente de la obra de Wilkinson e inspirados en esculturas del Rijksmuseum de Leiden que Alma-Tadema pudo estudiar en persona (Ebers, 1886, p. 45).

Curiosamente, las pinturas de la tumba de un segundo Nebamun también sirvieron de inspiración al artista en otros lienzos. Es el caso de Egyptian Chess Players 
(1865), una de las obras encargadas por Gambart al comienzo de su carrera que muestra a tres egipcios sentados en torno a un tablero. Este se encuentra extraído de los grabados de Wilkinson, al igual que otras piezas del mobiliario, los tocados de los personajes y la pintura que decora el muro del fondo, reproducida en el apartado de The Manners and Customs of the Ancient Egyptians dedicado a la agricultura. Como hemos mencionado, se trata de otro Nebamun coetáneo del que nos ocupa, también enterrado en el Valle de los Nobles y poseedor de un importante puesto como capitán de las tropas tebanas de la orilla oeste (Brooke Anthony, 2016, p. 109). Si bien las pinturas que adornan esta tumba no poseen la espectacularidad técnicas de las que hemos analizado, sí comparten bastantes similitudes en cuanto a la temática, haciendo hincapié una vez más en esa dualidad tan egipcia entre lo inexorable de la muerte y la obsesión por apurar los placeres de la vida.

\section{CONCLUSIONES}

Como hemos podido comprobar a lo largo de nuestro análisis, la influencia que ejercieron las pinturas de Nebamun sobre la pintura victoriana de finales del siglo XIX, y sobre Sir Lawrence Alma-Tadema en particular, es muy superior a la de cualquier otro ciclo pictórico del Antiguo Egipto. Ello se debe en gran medida a las circunstancias que rodearon su descubrimiento y posterior instalación en el Museo Británico, permitiendo de este modo una contemplación directa que no se pudo dar con otras representaciones, pero también al hecho de que sea uno de los conjuntos que mejor muestra la dualidad egipcia entre una existencia plena en el mundo de los vivos y las esperanzas depositadas en la ultratumba, entre el afán por apurar los goces terrenales y el convencimiento de que estos continuarían en el Más Allá. Sirva como ejemplo la fascinación de nuestro artista por escenas como la que representa un banquete en honor a Nebamun, cuya ambigüedad en cuanto al realismo de la misma (está plagada de detalles perfectamente reconocibles, pero puede mostrar también una celebración casi idéntica en el ámbito supraterrenal) es justamente uno de los detalles que acentuaron el interés de los pintores por esa temática.

Existía, además, otra circunstancia que jugaba a favor de este ciclo pictórico: el hecho de que no se tratara de representaciones de ningún faraón sino de un funcionario a su servicio que, pese a disfrutar de una situación acomodada, se encontraba más cerca del pueblo que de las divinidades. En una Inglaterra cuyo panorama artístico se hallaba dominado por la burguesía, siempre deseosa de demostrar lo mucho que merecía aquello que había conseguido ganar gracias a su esfuerzo, resultaba más sencillo establecer un mecanismo de identificación con sus equivalentes del Antiguo Egipto, por muchos siglos que mediaran entre ellos. Este paralelismo entre la Antigüedad y la contemporaneidad era precisamente uno de los sellos 
de identidad de la pintura de Alma-Tadema y lo que la convirtió en objeto de deseo por parte de la sociedad, al igual que sucedía con sus cuadros dedicados a la vida en Roma o en Pompeya; de algún modo, los pasatiempos y quehaceres profesionales de un José nombrado supervisor de los graneros reales o un patricio romano cómodamente instalado en su domus resultaban más familiares a sus clientes que las gestas de Ramsés II (1300-1213 a. de C.) o Julio César (100-44 a. de C.).

Ese es también el motivo por el cual nuestro artista decidió decantarse por temas intrascendentes, cualidad que no los hacía menos merecedores de interés. La supervisión de los gansos y el ganado de Nebamun y el banquete celebrado en su honor encontraron su equivalente en el José trabajando acompañado por su escriba y el baile organizado para agasajar a un embajador nubio retratados por Alma-Tadema. Lo mismo podría decirse si comparásemos su lienzo de los jugadores de ajedrez con pinturas de temática similar como la encontrada por Ernesto Schiaparelli (18561928) en 1904 en la sepultura de la reina Nefertari (fallecida en 1255 a. de C.), en una de cuyas escenas aparece representada con un juego de similares características conocido como senet. Son esta clase de detalles, fogonazos de la vida cotidiana, los que le permitían llevar a cabo la inmersión total del espectador en la escena, algo que se convirtió en una constante dentro de su producción.

Hemos visto también que su deseo de representar el mobiliario, los tocados, las vestimentas y la arquitectura de manera fidedigna le llevó a apoyarse en todo momento en la bibliografía sobre el Antiguo Egipto más en boga por entonces. La influencia de The Manners and Customs of the Ancient Egyptians resulta tan palpable en la pintura de Alma-Tadema como en la de sus colegas Poynter y Long. Con las pinturas de Nebamun ocurrió lo mismo, puesto que se trató, junto con los muebles conservados en el Museo Británico, de referentes con los que el artista pudo entrar en contacto por primera vez a través de los grabados de Wilkinson pero que después tuvo la oportunidad de estudiar personalmente en Londres, realizando sus propios estudios mediante acuarelas y dibujos.

Fue precisamente esa minuciosidad la que marcó un punto de inflexión en cuanto a la valoración de la pintura de Alma-Tadema por parte de los eruditos de su época. Lo que en otros artistas no pasó de ser mero detallismo esteticista se convirtió en sus lienzos en un análisis casi científico, que inevitablemente merecía la admiración de los estudiosos por su proximidad a la arqueología, la historia y la historia del arte. Podríamos decir, incluso, que este interés se encontraba cerca de la antropología, como deducimos de la elección de ciertos títulos como Pastimes in Ancient Egypt 3.000 Years Ago. El deseo de comparar los divertimentos de aquel entonces con los de la Inglaterra finisecular se encontraba presente también en el título anterior, How People Enjoyed Themselves 3.000 Years Ago; en ambos casos se pretendía deliberadamente que el público estableciera sus propias comparaciones entre ambas épocas, alejando la pintura del mero deleite estético característico de la corriente de Alma-Tadema para instar a un ejercicio de introspección. 
En el fondo, esa preocupación por el paso inexorable del tiempo, la caducidad de las obras creadas por la mano del hombre y el declive y caída de las civilizaciones de la Antigüedad no se encuentra alejada de la esencia de la mentalidad egipcia, si entendemos como tal el ciclo de la eterna regeneración convertido en una de sus señas de identidad. Como sostiene DeMaria Smith, era inevitable que estas reflexiones sobre las ruinas del pasado, herederas en gran medida de la sensibilidad del Romanticismo, calaran hondo en unos ingleses que se consideraban a sí mismos, por encima de todo, cabezas de un poderoso imperio, llevándoles a establecer con los antiguos egipcios una suerte de nexo espiritual $(2011,156)$. La obsesión con la eternidad, de alguna manera, acabó siendo el mejor mecanismo de actualización de las escenas plasmadas por Alma-Tadema, tanto como su minuciosa representación de ambientes, mobiliario o vestimentas de la época.

\section{REFERENCIAS BIBLIOGRÁFICAS}

Ash, R. (1999). Victorian Masters and Their Art. Londres: Pavilion Books.

Barrow, R. J. (2003). Lawrence Alma-Tadema. Londres: Phaidon Press.

Becker, E., Morris, E., Prettejohn, E. y Treuherz, J. (eds.). (1997). Sir Lawrence AlmaTadema. Exhibition Catalogue, Walker Art Gallery, Liverpool, and Van Gogh Museum, Amsterdam. Nueva York: Rizzoli.

Brooke Anthony, F. (2016). Foreigners in Ancient Egypt: Theban Tomb Paintings from the Early Eighteenth Dynasty. Londres: Bloomsbury Publishing.

Chang, A. W. (2017). Staging Ethnicity: Edvard Munch's Images of Sultan Abdul Karim. En A. Childs y S. Libby (eds.), Blacks and Blackness in European Art of the Long Nineteenth Century. Londres: Ashgate.

Conner, P. (ed.). (1983). The Inspiration of Egypt: Its Influence on British Artists, Travellers, and Designers, 1700-1900. Brighton: Brighton Borough Council.

DeMaria Smith, M. (2011). HRH Cleopatra: The Last of the Ptolemies and the Egyptian Paintings of Sir Lawrence Alma-Tadema. En M. Miles (ed.), Cleopatra: A Sphinx Revisited (pp. 150-171). Los Ángeles: University of California Press.

Ebers, G. (1886). Lorenz Alma Tadema: His Life and Works. Nueva York: W. S. Gottsberger. 
Esposito, D. (2003). From Ancient Egypt to Victorian London: The Impact of Ancient Egyptian Furniture on British Art and Design 1850-1900. The Journal of the Decorative Arts Society 1850-the Present, 27, pp. 80-93.

Fritze, R. H. (2016). Egyptomania: A History of Fascination, Obsession and Fantasy. Londres: Reaktion.

Gaunt, W. (1953). Victorian Olympus. Londres: Non-Fiction Book Club.

Hooper, M. (2008). The Tomb of Nebamun. Londres: British Museum Press.

Huckvale, D. (2012). Ancient Egypt in the Popular Imagination: Building a Fantasy in Film, Literature, Music and Art. Jefferson: McFarland \& Company.

Humbert, J.-M. y Price, C. (eds.). (2012). Imhotep Today: Egyptianized Architecture. Londres: Cavendish Publishing.

Manley, D. y Rée, P. (2002). Henry Salt: Artist, Traveller, Diplomat, Egyptologist. Londres: Libri.

McCouat, P. (2015). Lost masterpieces of ancient Egyptian art from the Nebamun tomb-chapel. Journal of Art in Society. Recuperado el 21 de febrero de 2019, de <http://www.artinsociety.com/lost-masterpieces-of-ancient-egyptian-artfrom-the-nebamun-tomb-chapel.html>.

Meulenaere, H. de (1992). Ancient Egypt in Nineteenth Century Painting. KnokkeHeist: Berko.

Middleton, A. y Uprichard, K. (2008). The Nebamun Wall Paintings: Conservation, Scientific Analysis and Display at the British Museum. Londres: Archetype Publications.

Moser, S. (2006). Wondrous Curiosities: Ancient Egypt at the British Museum. Chicago: Chicago University Press.

Moser, S. (2015). Reconstructing Ancient Worlds: Reception Studies, Archaeological Representation and the Interpretation of Ancient Egypt. Journal of Archaeological Method, 22(4), pp. 1263-1308. 
Moser, S. (2018). The Beauty of Antiquity: Egypt in the art of Alma-Tadema, Poynter and Long: Antiquities and ancient Egypt in the art of Lawrence Alma Tadema, Edward John Poynter and Edwin Long. Nueva York: Oxford University Press.

Pohlmann, U. (1997). Alma-Tadema and Photography. En E. Becker, E. Morris, E. Prettejohn y J. Treuherz (eds.), Sir Lawrence Alma-Tadema. Exhibition Catalogue, Walker Art Gallery, Liverpool, and Van Gogh Museum, Amsterdam (pp. 111-114). Nueva York: Rizzoli.Prettejohn, E. (1997). Antiquity fragmented and reconstructed: Alma-Tadema's compositions. En E. Becker, E. Morris, E. Prettejohn y J. Treuherz (eds.), Sir Lawrence Alma-Tadema. Exhibition Catalogue, Walker Art Gallery, Liverpool, and Van Gogh Museum, Amsterdam (pp. 33-44). Nueva York: Rizzoli.

Raven, M. J. (1980). Alma Tadema als amateur-egyptoloog. Bulletin van het Rijksmuseum, 28(3), pp. 103-117.

Richards, J. (2009). The Ancient World on the Victorian and Edwardian Stage. Basingstoke: Palgrave Macmillan.

Said, E. W. (1994). Culture and Imperialism. Londres: Vintage.

Said, E. W. (2003). Orientalism. Londres: Penguin.

Swanson, V. G. (1990). Alma-Tadema: The Biography and Catalogue Raisonné of the Paintings of Sir Lawrence Alma-Tadema. Londres: Garton and Co Print Dealers and Publishers.

Taylor, J. H. (2016). An unusual funerary figurine of the early $18^{\text {th }}$ Dynasty. En C. Price, R. Forshaw, A. Chamberlain y P. T. Nicholson (eds), Mummies, Magic, and Medicine in Ancient Egypt: Multidisciplinary Essays for Rosalie David (pp. 210-228). Oxford: Oxford University Press.Thompson, J. (2010). Sir Gardner Wilkinson and His Circle. Austin: University of Texas Press.

Vaizey, M. (1982). The Artist as Photographer. Londres: Sidgwick \& Jackson.

Verhoogt, R. (2007). Art in Reproduction: Nineteenth-century Prints After Lawrence Alma-Tadema, Jozef Israels and Ary Scheffer. Ámsterdam: Amsterdam University Press.

Verhoogt, R. (2018). Alma-Tadema's Egyptian dream: ancient Egypt in the work of Sir Lawrence Alma-Tadema. Nineteenth Century Contexts, 40(1), pp. 1-19. 
Volait, M. (2013). Émile Prisse d`Avennes: un artiste-antiquaire en Égypte au XIXe siècle. El Cairo: Institut français d'archéologie orientale.

Wallis Budge, E. A. (2010). The Mummy: A Handbook of Egyptian Funerary Archaeology. Cambridge: Cambridge University Press.

Wilkinson, J. G. (1837-1840). The manners and customs of the ancient Egyptians. Londres: John Murray. 